\title{
Internal Oblique Muscle
}

National Cancer Institute

\section{Source}

National Cancer Institute. Internal Oblique Muscle. NCI Thesaurus. Code C32857.

A large thin muscle beneath the external oblique that stretches from the iliac crest to the inferior borders of the tenth to twelfth ribs and the abdominal midline which act to bend the upper trunk forward. 